\title{
PENGARUH EKSTRAK RIMPANG JAHE (ZINGIBER OFFICINALE ROSC.) TERHADAP PERTUMBUHAN PYTHIUM SP. PENYEBAB PENYAKIT REBAH KECAMBAH MENTIMUN SECARA IN VITRO
}

\author{
Subli Mujim ${ }^{1}$
}

\begin{abstract}
Effect of the ginger extract (Zingiber officinale Rosc.) on the growth of Pythium sp., the causal agent of cucumber damping off disease. The Pythium sp. often damaged cucumber seedling in seedbed. The objective of this study was to evaluate the effectiveness of ginger extract on the growth and spore production of Pythium sp. The study was conducted in 2005 at the laboratory of plant pathology, University of Lampung. The treatments were arranged in a completely randomized design with four replicates. The treatments were consisted of five level of concentrations of ginger rhizome extract i.e, $0 ; 2.5$; $5.0 ; 7.5$ and $10 \%$. The results show that all concentrations of the rhizome ginger extract inhibited mycelial growth and spore production of Pythium sp. There was a significant linear relationship between the rhizome ginger extract and both of fungal growth and spore production.
\end{abstract}

Key words: extract, ginger rhizome, cucumber damping off, fungal growth

\section{PENDAHULUAN}

Penyakit rebah kecambah (damping off) yang disebabkan oleh jamur tular tanah Pythium sp. merupakan penyakit yang sering merugikan pada tanaman mentimun (Imdad \& Nawangsih, 1999). Menurut Agrios (2005), Pythium sp. dapat menyerang dan mematikan biji mentimun yang baru ditanam, bahkan sering menyerang perakaran dan batang yang belum muncul ataupun yang baru muncul ke permukaan tanah. Serangan jamur Pythium sp. akan lebih parah bila didukung oleh kelembaban tanah yang tinggi (Suleiman \& Emua, 2009). Beberapa cara yang telah dilakukan untuk mengendalikan penyakit rebah kecambah antara lain penanaman benih yang baik, penggunaaan varietas unggul, pengurangan kelembaban tanah dan penggunaan fungisida sintetik. Namun usaha pengendalian tersebut belum menunjukkan hasil yang memuaskan. Walaupun penggunaan fungisida sintetik cukup efektif, namun selain harganya mahal dapat pula menimbulkan dampak negatif terhadap lingkungan dan kesehatan manusia apabila dilakukan dengan kurang bijaksana. Usaha pengendalian dengan alternatif lain yang bersifat ramah lingkungan perlu dilakukan agar penyakit rebah kecambah pada mentimun dapat ditekan.
Salah satu alternatif yang dapat dilakukan adalah pemanfaatan fungisida nabati. Fungisida nabati memiliki keunggulan dibandingkan dengan fungisida sintetik, karena mudah terurai, mudah diaplikasikan, bahan mudah didapat serta aman terhadap lingkungan dan kesehatan manusia. Menurut Kardinan (2002), pestisida nabati memiliki senyawa kimia yang dapat menghambat pertumbuhan jamur sasaran. Salah satu tanaman yang dapat digunakan sebagai fungisida nabati adalah tanaman jahe (Zingiber officinale Rosc.). Menurut Prakash \& Rao (1997), tanaman jahe terdapat melimpah di Indonesia. Tanaman jahe diduga dapat berperan sebagai pestisida nabati, karena rimpang tanaman jahe mengandung 2-3\% minyak atsiri, 20-60\% pati, damar, asam organik, asam malat, asam oksalat serta gingerin (Mursito, 2003). Menurut Paimin \& Murhananto (2002), tanaman jahe mempunyai kemampuan dalam menghambat pertumbuhan jamur dan bakteri.

Penelitian ini bertujuan untuk mengetahui kemampuan ekstrak rimpang jahe terhadap pertumbuhan Pythium sp. penyebab penyakit rebah kecambah pada tanaman mentimum secara in vitro. Diharapkan hasil penelitian ini dapat menjadi suatu alternatif baru dalam pengendalian penyakit rebah kecambah yang ramah terhadap lingkungan.

\footnotetext{
${ }^{1}$ Jurusan Proteksi Tanaman, Fakultas Pertanian, Universitas Lampung,

Jl. Prof. Sumantri Brodjonegoro No. 1 Bandar Lampung 35145. E-mail : sublimujim@unila.ac.id dan sublimujim@yahoo.com
} 


\section{METODE PENELITIAN}

Penelitian dilaksanakan secara in vitro di Laboratorium Penyakit Tumbuhan, Jurusan Proteksi Tanaman, Fakultas Pertanian Universitas Lampung tahun 2005. Perlakuan disusun dalam Rancangan Acak Lengkap dengan empat ulangan. Perlakuan terdiri atas lima aras konsentrasi ekstrak rimpang jahe, yaitu $0 ; 2,5$; 5; 7,5 dan $10 \%$. Data hasil pengamatan dianalisis dengan sidik ragam dan dilanjutkan dengan uji ortogonal polinomial. Isolat Pythium sp. diperoleh dari buah mentimun yang terserang Pythium sp. Isolasi jamur dilaksanakan dengan cara buah mentimum yang terserang Pythium sp. dicuci bersih dengan air kran dan dibilas dengan aquadest steril, lalu diinkubasi selama tiga hari. Koloni jamur yang tumbuh pada permukaaan kulit mentimun secara aseptik diisolasi ke dalam media PDAasam laktat (PDA-L). Setelah jamur tersebut tumbuh, lalu ditransfer beberapa kali ke media PDA-L yang lain dengan metode ujung hifa (hyphal tips) sampai didapatkan kultur murni.

Pembuatan ekstrak jahe dilakukan dengan cara mencuci rimpang jahe dengan air kran sampai bersih, lalu dibilas beberapa kali dengan aquadest steril, selanjutnya dikeringanginkan. Rimpang jahe yang sudah kering dipotong kecil-kecil, lalu ditimbang sebanyak 100 $\mathrm{g}$, dan dicampur dengan $100 \mathrm{ml}$ aquadest steril (berat/ volume 1:1), kemudian diblender. Setelah diblender hingga halus, campuran tersebut disaring dengan empat lapis kain kasa steril guna mendapatkan ekstrak rimpang jahe berupa aliquot. Ekstrak rimpang jahe yang didapat, sesuai dengan masing-masing konsentrasi ekstrak yang telah ditetapkan sebagai perlakuan dimasukkan ke dalam media PDA-L dalam empat labu Erlenmeyer, lalu diotoklaf selama 20 menit pada suhu $121^{\circ} \mathrm{C}$ dengan tekanan $1 \mathrm{~atm}$. Setelah media di dalam labu erlenmeyer agak dingin, lalu dituangkan ke dalam masing-masing cawan petri sebanyak $10 \mathrm{ml}$ sesuai perlakuan. Selanjutnya ke dalam masing-masing cawan petri yang telah diisi tersebut (dalam keadaan membeku), di tengahtengahnya diletakkan potongan (cuplikan) koloni Pythium sp. berdiameter $10 \mathrm{~mm}$, kemudian semua cawan petri tersebut diinkubasikan pada suhu ruangan dengan 12 jam gelap dan 12 jam cahaya lemah. Pertumbuhan jamur diamati setiap 12 jam, dan dihentikan bila pertumbuhan jamur pada perlakuan kontrol telah memenuhi cawan petri. Pengukuran pertumbuhan jamur dilakukan dengan mengukur diameter koloni sebagai peubah. Pengukuran diameter koloni jamur selalu dikurangi dengan diameter potongan koloni awal yang berukuran $10 \mathrm{~mm}$.
Selain pengukuran diameter koloni jamur, pengamatan juga dilakukan dengan menghitung produksi spora jamur Pythium sp. pada saat jamur tersebut berumur tujuh hari. Penghitungan jumlah spora dilakukan dengan cara mengambil cuplikan jamur pada lima titik secara diagonal pada cawan petri dengan jarak $2 \mathrm{~cm}$ dari pusat (titik tengah cawan petri) dengan menggunakan bor gabus, kemudian hasil cuplikan dimasukan ke dalam $5 \mathrm{ml}$ air steril dalam tabung reaksi sebagai suspensi spora. Suspensi yang didapat dihomogenkan dengan rotamixer. Setelah homogen diambil sebanyak $0,1 \mathrm{ml}$ dan dimasukkan ke dalam haemocytometer dan dilakukan perhitungan jumlah spora.

\section{HASIL DAN PEMBAHASAN}

Pertumbuhan Pythium sp. Hasil uji ortogonal polinomial terhadap pengaruh berbagai aras konsentrasi ekstrak rimpang jahe dalam menekan pertumbuhan jamur Pythium sp. menunjukkan terjadinya pengurangan diameter koloni jamur Pythium sp. secara linier pada pengamatan 96 jam setelah aplikasi jamur Pythium sp. pada cawan petri berisi PDA-L dengan persamaan : Y $=3,181-0,1637 \mathrm{X}$ dan $\mathrm{r}=-0,753$ (Gambar 1).

Gambar 1 menunjukkan hubungan antara konsentrasi ekstrak jahe dengan ukuran diameter koloni Pythium sp. yang bersifat linier dimana semakin tinggi konsentrasi ekstrak rimpang jahe yang digunakan, semakin mengurangi ukuran diameter koloni jamur Pythium sp. Pengamatan yang dilakukan terhadap pengaruh ekstrak rimpang jahe pada 96 jam setelah aplikasi menunjukkan bahwa terjadi penghambatan diameter koloni jamur Pythium sp. baik pada konsentrasi $2,5 \% ; 5 \% ; 7,5 \%$ dan $10 \%$. Namun demikian konsentrasi ekstrak $10 \%$ memiliki kemampuan paling tinggi dalam menekan pertumbuhan koloni jamur Pythium sp. dibandingkan dengan konsentrasi lainnya.

Produksi Spora. Hasil uji ortogonal polinomial terhadap pengaruh berbagai aras konsentrasi ekstrak rimpang jahe dalam menekan produksi spora jamur Pythium sp. menunjukkan terjadinya penurunan jumlah produksi spora secara linier pada pengamatan tujuh hari setelah aplikasi Pythium sp. pada cawan petri berisi PDA-L dengan persamaan : $Y=6,857-0,0921 X$ dan $r=-0,921$ (Gambar 2).

Gambar 2 memperlihatkan hubungan antara konsentrasi ekstrak jahe dan produksi spora yang bersifat linier dimana semakin tinggi konsentrasi ekstrak rimpang 


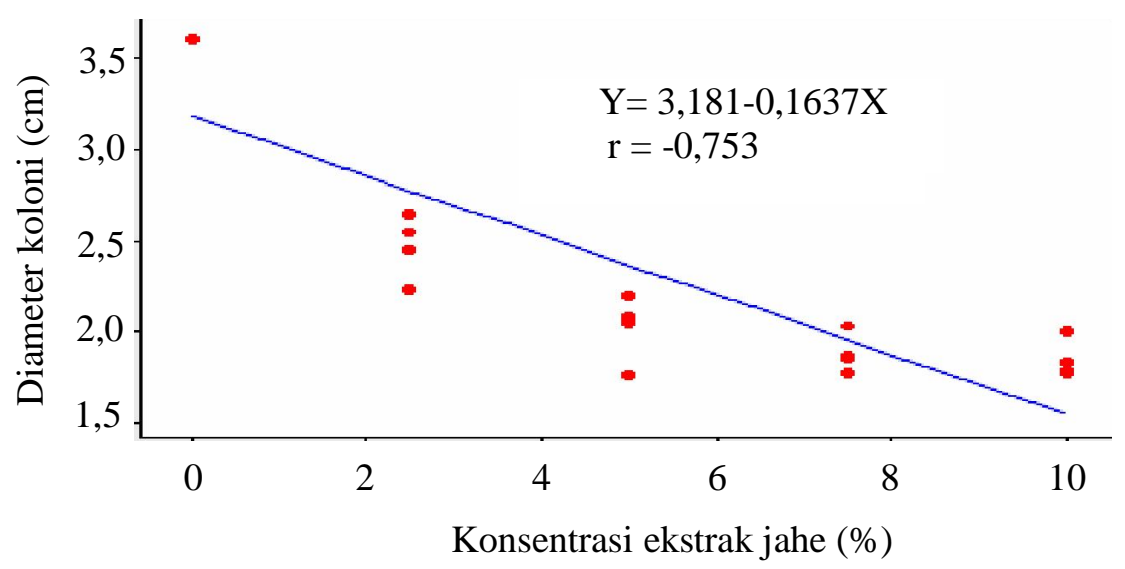

Gambar 1. Hubungan konsentrasi ekstrak jahe dengan diameter koloni pada pengamatan 96 jam setelah aplikasi Pythium sp.

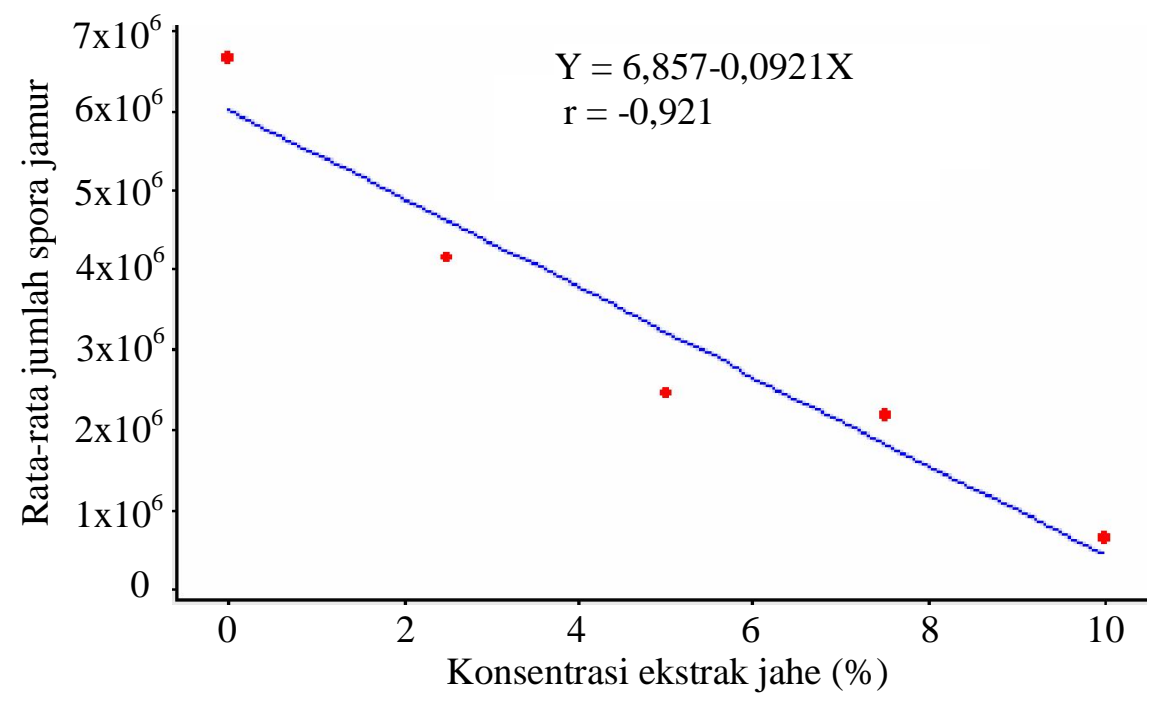

Gambar 2. Hubungan antara konsentrasi ekstrak jahe dengan produksi spora pada pengamatan 7 hari setelah aplikasi Pythium sp. 
jahe yang digunakan, semakin menurunkan jumlah spora jamur Pythium sp.

Dengan demikian perlakuan ekstrak rimpang jahe pada berbagai aras konsentrasi berpengaruh nyata dalam menghambat pertumbuhan dan produksi spora jamur Pythium sp. secara in vitro. Semakin tinggi konsentrasi ekstrak rimpang jahe yang digunakan semakin berkurang ukuran diameter koloni jamur, dan produksi spora Pythium sp. juga semakin menurun. Pengurangan diameter koloni dan penurunan jumlah spora jamur Pythium sp. tersebut mungkin dikarenakan pada aras konsentrasi ekstrak rimpang jahe yang tinggi mengandung senyawa anti jamur yang lebih banyak sehingga semakin banyak senyawa anti jamur yang diserap oleh jamur Pythium sp., dan akhirnya menyebabkan pertumbuhan jamur menjadi tertekan. Temuan ini sejalan dengan hasil penelitiaan Suleiman \& Emua (2009) di Nigeria yang menyatakan bahwa semakin tinggi konsentrasi ekstrak jahe yang dipakai, semakin efektif dalam menekan pertumbuhan jamur Pythium sp. yang menyebabkan penyakit rebah kecambah pada tanaman kacang buncis. Ginting et al. (2004) menyatakan bahwa jamur Hemileia vastatrix (penyebab penyakit karat daun kopi) tidak mampu tumbuh pada cakram daun kopi yang telah diaplikasi dengan ekstrak rimpang jahe.

Senyawa kimia yang diduga berperan dalam rimpang jahe adalah minyak atsiri (Paimin \& Murhananto, 2002). Minyak atsiri dalam rimpang jahe sebagian besar terdiri atas zingeton/gingerol atau metil keton, zingiberol, zingiberin, borneol, kamfen, sineol, falandren, pati, damar, asam organik, oleoresin dan gingerin (Kartasapoetra, 1996). Menurut Robinson (1991), senyawa sineol dan turunan golongan fenilpropana merupakan senyawa aromatik yang memiliki daya racun sehingga dapat berfungsi sebagai fungisida.

Senyawa lain yang terdapat pada minyak atsiri dalam rimpang jahe antara lain : n-desil aldehid, n-nonil aldehid, d-kamfen, d-a-falandren, metil heptenon, sineol, d-borneol, linalool, asetat, kaprilat, kavicol, fenol dan limonen (Syukur, 2001). Diduga kandungan fenol pada minyak atsiri yang terdapat dalam ekstrak jahe tersebut berperan penting dalam menekan pertumbuhan dan produksi spora jamur Pythium sp. Masih diperlukan penelitian lanjutan untuk menentukan senyawa kimia yang mana yang paling berperan dalam menekan pertumbuhan jamur Pythium sp. tersebut. Menurut
Agrios (2005), tumbuhan menghasilkan senyawa fenol yang dapat menghambat pertumbuhan jamur. Senyawa anti jamur yang terkandung dalam ekstrak rimpang jahe diduga merusak permeabilitas membran sel dan mengganggu proses enzimatis jamur sehingga pertumbuhannya menjadi terhambat.

Penurunan jumlah spora pada perlakuan dengan ekstrak rimpang jahe diduga karena kualitas miselium sudah dirusak terlebih dahulu oleh senyawa-senyawa yang terkandung dalam ekstrak jahe sehingga miselium tersebut tidak mampu menghasilkan spora yang lebih banyak. Hal ini sangat menguntungkan karena spora merupakan alat penyebaran patogen yang paling penting.

\section{SIMPULAN}

Berdasarkan hasil penelitian ini, dapat disimpulkan bahwa ekstrak rimpang jahe pada berbagai aras konsentrasi mampu menekan pertumbuhan dan produksi spora jamur Pythium sp. penyebab penyakit rebah kecambah pada mentimun secara in vitro. Semakin tinggi konsentrasi ekstrak rimpang jahe, semakin efektif dalam menekan pertumbuhan dan produksi spora jamur Pythium sp.

\section{DAFTAR PUSTAKA}

Agrios GN. 2005. Plant Pathology. 5th Ed. Elsevier Academic Press, Burlington.

Ginting C, Mujim S \& Evizal R. 2004. Uji pendahuluan pengaruh ekstrak air dari tumbuhan terhadap keterjadian karat pada cakram daun kopi di laboratorium. J. Hama dan Penyakit Tumbuhan Tropika 4(1): 47-51.

Imdad P \& Nawangsih A. 1999. Sayuran Jepang. Penebar Swadaya. Jakarta.

Kardinan A. 2002. Pestisida Nabati. Ramuan dan aplikasi. Penebar Swadaya. Jakarta.

Kartasapoetra G. 1996. Budidaya Tanaman Berkhasiat Obat. Rineka Cipta. Jakarta.

Mursito B. 2003. Sehat di usia lanjut dengan ramuan tradisional. Penebar Swadaya. Jakarta. 
Paimin FB \& Murhananto. 2002. Budidaya, pengolahan, dan perdagangan jahe. Penebar Swadaya. Jakarta.

Prakash A \& Rao J. 1997. Botanical Pesticides in Agriculture. CRC Press, Inc.

Robinson T. 1991. Kandungan organik tumbuhan tinggi. Diterjemahkan oleh Kosasih Pancawinata. ITB. Bandung.
Suleiman MN \& Emua SA. 2009. Efficacy of four plant extracts in the control of root rot disease of cowpea (Vigna unguiculata [L.] Walp). African J. Biotechnology 8(16): 3806-3808.

Syukur C. 2001. Agar jahe berproduksi tinggi. Penebar Swadaya. Jakarta. 